\title{
O lúdico e o sério: experiências com jogos no ensino de história
}

Débora El-jaick Andrade*

\section{RESUMO}

Este artigo tem como objetivo discutir o papel do jogo no aprendizado de História apresentando como exemplo atividades experiências realizadas na rede pública do ensino fundamental no Rio de Janeiro entre os anos de 2001 e 2007. Analisa as características do jogo, simultaneamente lúdico e sério, que propiciam resultados positivos ao estimular os alunos a analisar, sintetizar e manipular conceitos e saberes necessários à construção do conhecimento histórico.

Palavras -chaves: Lúdico, Jogos, Ensino de história, Estratégias de aprendizado

\section{0 lúdico e o sério: experiências com jogos no ensino de história}

Nas últimas décadas educadores e teóricos da educação têm dedicado grande atenção às potencialidades dos jogos, brinquedos educativos e atividades lúdicas para auxiliar e tornar possíveis as condições de aprendizado de crianças em idade escolar. Apesar dos jogos existirem como recurso ou instrumento pedagógico desde o Romantismo, os estudos sobre seu significado e importância se intensificaram no século XX. Autores como Piaget, Brougère, Huizinga, Caillois, Montessori, Vygostsky, entre outros deram importantes contribuições, identificando a função dos brinquedos e jogos na psicologia infantil e no desenvolvimento cognitivo.

No cotidiano das salas de aula, diversas formas de jogos e competições são empregadas e reconhecidas como meio de estimular o desenvolvimento de crianças e jovens. Jogos e brinquedos educativos são elaborados para portadores de necessidades especiais, para desenvolver o raciocínio lógico nas aulas de

\footnotetext{
* Doutoranda em História pela UFF - professora efetiva do Colégio Pedro II - Rio de Janeiro - RJ.
} 
matemática, para facilitar a compreensão escrita e oral e incentivar a relação e a solidariedade de grupo e o trabalho em equipe.

Frequientemente os educadores utilizam modalidades de jogos sem terem clareza dos objetivos e resultados destas propostas pedagógicas. Utilizam como recursos como jograus, palavras cruzadas, gincanas, questionários, olimpíadas, feiras de conhecimentos, forca, xadrez, adivinhação. As habilidades que estimulam são entendidas como finalidades em si, mas esquece-se do jogo, o que ele ensina e como pode, se bem planejado, potencializar a estruturação e a re-significação dos saberes escolares. Propriedades dos jogos como a estética, liberdade e ludicidade auxiliam na identificação do aluno com o conhecimento, motivando-o a usar sua inteligência para jogar bem, isto é, superar obstáculos cognitivos e emocionais.(KISHIMORO, 2005, p.96)

o jogo se caracteriza como livre, no sentido que a adesão a ele deve ser espontânea, é delimitado porque requer definições combinadas de tempo e espaço, é incerto, pois não é possível prever resultados, improdutivo já que enquanto atividade não produz riqueza, regulamentado porque sujeita os participantes a regras próprias do jogo e é fictícia porque opera em um contexto de simulação e irrealidade em relação à vida normal.(MACEDO, 2006, p.18)

Johan Huizinga dedicou seu livro Homo ludens a caracterização do jogo, não apenas como parte integrante da cultura, mas como precedente a ela. 0 jogo é entendido como uma função significante que confere sentido à ação, e se baseia na manipulação de imagens, de certa imaginação da realidade. De acordo com o autor, o jogo se destaca da vida comum posto que é uma atividade temporária e de duração limitada, situando-se fora da satisfação imediata das necessidades. É atividade livre em que os participantes entram espontaneamente, mas embora seja tomada como "não séria", efetua-se sempre no maior espírito de seriedade. No jogo há beleza, harmonia, ritmo, que inspiram fascínio, tensão, alegria e divertimento, mas há também ordem e as regras estabelecidas devem ser seguidas por todos. Uma vez quebradas as regras, destrói-se a ilusão do jogo. (HUIZINGA, 1998, p.14)

O caráter lúdico do jogo está relacionado ao aspecto afetivo envolvido nesta atividade e se manifesta na liberdade de sua prática. Esta liberdade está todavia, inserida num sistema que a define por meio de regras, o que é aceito espontaneamente por aqueles que jogam, condição necessária para a existência de qualquer jogo. 
Impõe-se, então um desafio, uma tarefa, uma dúvida ao jogar, entretanto é o próprio sujeito quem impõe a si mesmo resolvê-los para "provar seu poder e sua força mais para si mesmo que para os outros". (FERMINANO, 2005, p.3)

Assim, é no caráter ao mesmo tempo lúdico e educativo que reside o "paradoxo do jogo". Suas qualidades o tornam um recurso eficaz para o educador criar e organizar as condições para a aprendizagem ou maximizar a construção de saberes e noções anteriormente trabalhados. (KISHIMOTO, 2005, p.37) Concorre para esta eficácia o fato de crianças e adolescentes geralmente estarem familiarizados com variadas modalidades de jogos e competições no ambiente extra escolar.

Tem-se argumentado que as transformações sociais no século XX com o crescimento dos centros urbanos, intensificação da violência e dos conflitos, a inserção das escolas nas comunidades faveladas, a sociedade de consumo de massa tem modificado a infância. As crianças que até metade do século XX brincavam na rua, no quintal, nas praças, encontram poucas ocasiões para praticar atividades ou jogos e brincadeiras fora do próprio domicílio. A sociedade de consumo de massa foi responsável por transformações sobre as características da infância e dos objetos consumidos pelas crianças para brincadeiras. Atualmente crianças e adolescentes especialmente dos estratos médios, se acostumaram ao tipo de jogos individuais eletrônicos que requerem pouca construção imaginativa ou ainda aos jogos esportivos em clubes ou play grounds. Por vezes as exigências de horários e de desempenho escolar retiram da criança a possibilidade de escolher a atividade lúdica a qual se dedicar. Os jovens filhos das classes populares geralmente limitados pela violência ou pelo universo cultural em que se inserem, divertem-se com futebol em campinhos ou empinando pipa, sujeitos à ação do tráfico ou a da polícia.

Os espaços para as brincadeiras vão se limitando, ocorrendo uma desvalorização da atividade lúdica, em que o brincar ou o brinquedo também se transformaram em consumo e em um mercado promissor para a indústria e para o capital.(ALMEIDA, 2006) Como adequadamente apontou Walter Benjamim, a era da tecnologização avassaladora apagava da memória brinquedos antigos, como o peão, a bolinha de gude, soldado de chumbo, quase artesanais e brincadeiras tradicionais como pique esconde, amarelinha, corda, que engendravam um processo de imaginação e a participação de outras crianças e mesmo dos adultos no processo. Jogos e divertimentos na modernidade ganham uma escala individualizante em 
que o objeto de consumo em si tem valor e nem tanto a ação do brincar. Jogos como baralho, palavras cruzadas e batalha naval começam a ficar distantes da realidade das novas gerações. Principalmente os jogos realizados coletivamente perdem espaço para vídeo games e jogos virtuais que não requerem elaboração imaginativa posto que os desafios destes jogos nascem pré-programados, retirando da criança as possibilidades e liberdades do jogo e o processo de criação e a fantasia.(ALMEIDA, 2006)

A escola, longe de passar a margem deste processo, insere-se dentro da cultura e da sociedade, aceitando as mudanças ou reagindo a elas. Como sugere Foucault, existem na sociedade relações de poder múltiplas que a atravessam, caracterizam e constituem o corpo social e que não podem ser dissociados, se estabelecer nem funcionar sem uma produção, acumulação circulação e funcionamento do discurso da verdade. (FOUCAULT, 1979, p.179). Na sociedade capitalista como a nossa o poder engendra múltiplas sujeições que existem e funcionam no corpo social, assim como produz discursos e regras que condenam, classificam, vigiam os corpos e os comportamentos e obrigam as pessoas a viver de determinada forma. A escola é uma instituição em que estes poderes se materializam e se dá a imposição dos saberes, mas também nela, como em todas as instâncias do social, reside a contradição, a dissonância.

Embora transpassado pelo poder e pelos discursos do poder, o ambiente escolar é ainda neste contexto, um espaço privilegiado para se restabelecer a importância de jogos coletivos que estimulem a concentração, o raciocínio e a cooperação, a competição, a experimentação e a auto afirmação, em que crianças ou adolescentes com mais ou menos a mesma idade e interesses, escapam temporariamente das exigências e dificuldades do mundo moderno. 0 educador, enquanto intelectual consciente dos objetivos e meios para 0 processo de ensino-aprendizagem pode dirigir, propor, e planejar novas estratégias adequadas as possibilidades e limitações da escola e da comunidade em que exerce sua função. Constatamos que as atividades físicas, são enxergados pelos jovens como espaços de liberdade, distante das regras e exigências impostas pelas demais disciplinas escolares. Contudo, o entusiasmo pelo "fugir das regras" não é atributo apenas de disciplinas como artes, teatro ou educação física. Em qualquer área do conhecimento este espaço de liberdade e ludicidade pode ser construído sem que os objetivos pedagógicos, o conhecimento científico, a seriedade e o planejamento docente sejam sacrificados. 
Percebemos que o conhecimento histórico em nossa disciplina é imensamente aberto aos recursos lúdicos e que estes não são apenas instrumentos de motivação, mas interferem e conferem significados singulares às noções e conteúdos que se queira trabalhar.Teatrinhos sobre determinados eventos históricos, histórias ou poemas construídos por eles sobre o modo de vida de pessoas de outras épocas, histórias em quadrinhos ilustrando textos lidos, pesquisas, cartazes, filmes são utilizações de diferentes e "novas linguagens" que alcançam os jovens fora do espaço da escola. 0 jogo enquanto linguagem é um dispositivo privilegiado neste sentido porque como elemento de cultura está presente na sociedade em diferentes formas, nos programas de televisão, como jogos esportivos disputados entre os clubes e nações, como mercadoria nas lojas, como instrumento pedagógico na pré-escola, ou ainda como lazer ilícito no caso dos jogos de azar.

A partir destas atividades e experiências os jovens constroem noções de temporalidades, comparações, noções de processos e transformações, operações de identificação e diferenciação que lhes permitem conhecer diferentes realidades históricas e refletir sobre sua própria realidade.

Apresentamos neste artigo algumas experiências a propósito da utilização de jogos nas aulas de história. Em uma escola municipal localizada no bairro de Cidade de Deus, na Zona Oeste do Rio de Janeiro, tivemos a oportunidade de testar as qualidades do jogo enquanto uma nova linguagem na educação. Para tanto foi preciso conhecer a comunidade, aproveitar os saberes anteriores compartilhados e trazidos pelos alunos. 0 corpo docente realizava projetos que envolviam o resgate da auto estima e da identidade das crianças alunos daquela comunidade muito pobre e estigmatizada no Rio de Janeiro.

0 cotidiano das aulas nesta escola verificava-se que os alunos apresentavam dificuldades de leitura, liam devagar, decodificando as sílabas lentamente, mas sem compreender o sentido das palavras e frases. 0 desinteresse e a falta de compreensão em relação aos programas das disciplinas escolares eram evidenciados pelas provas entregues quase sempre em branco. Este processo é analisado pelo sociólogo Pierre Bourdieu, que conclui que a escola ao invés de ser um fator de mobilidade social, legitima as desigualdades sociais e colabora para conservação social, pois através de muitas seleções e exclusões, crianças e jovens de camadas superiores têm chances muito maiores de ter êxito escolar e 
chegar à universidade do que jovens das classes populares. Bourdieu atribuiu esta constatação ao privilégio cultural, que exclui famílias de baixo nível de escolaridade e capital cultural do acesso a práticas e conhecimentos culturais e a facilidade lingüística. (BOURDIEU, 1998, p.41-45) Assim os saberes formais científicos e a linguagem acadêmica pertencentes aos livros didáticos, seguem a norma culta da linguagem e distanciam-se da realidade concreta e no universo de interesses e familiaridades da maioria dos alunos na rede pública municipal. Os saberes, gostos, a cultura e princípios transmitidos e compartilhados por estas crianças e adolescentes eventualmente se revelam estranhos ou conflitantes com aquelas dos educadores.

A consequiência mais alarmante deste estranhamento é a dificuldade do manejo da língua materna, de compreender o que se lê e de produzir textos, ferramentas de trabalho necessárias para os estudantes aprenderem a pesquisar e buscar informações em diversos registros lingüísticos e aportes textuais, que thes capacitariam ampliar sua compreensão de mundo.

Diante das dificuldades encontradas trabalhando com uma turma de $6^{a}$ série do ensino fundamental procurei adaptar os programas curriculares, entendo "que como importante terreno de luta cultural, a cultura do aluno da classe trabalhadora precisa torna-se parte de uma pedagogia voltada para seus interesses e necessidades". (MOREIRA, 1972, p.37) A exemplo de outras disciplinas que conquistavam a receptividade dos estudantes através de atividades lúdicas, o xadrez na aula de matemática, gincanas em música, esporte em educação física, optamos por explorar o interesse difundido na comunidade pelo tema da atualidade: Bin Laden, o terrorismo e a guerra no Afganistão. Logo após a derrubada das Torres Gêmeas, em setembro de 2001, o tráfico de drogas do local incentivou uma certa mitificação dos terroristas da Al-Qaeda, associando-os aos "heróis" do "movimento", em função de vagas semelhanças na metodologia de atuação, rebeldia e condição de marginalidade.

Percebemos que assunto era corrente entre a meninada e optamos por aproveitar este interesse para desenvolver um trabalho sobre o Islamismo, sua origem e expansão pelo mundo, aproveitando para introduzir noções sobre a história do Oriente Médio e do imperialismo na região. Em associação com uma série de outros recursos e estratégias como leitura de textos de enciclopédias, filmes, palavras cruzadas, elaboramos um jogo destinado a levar os alunos à 
leitura. Recortamos notícias de três jornais diferentes a propósito da guerra no Afganistão. Dividimos as reportagens em temas: os ataques americanos a alvos civis no Afganistão, interesses norte americanos no Oriente Médio, a reação internacional ao terrorismo, o sofrimento de crianças e mulheres após a destruição. Em seguida colamos uma reportagem de cada tema em cartolinas e elaboramos um resumo para cada reportagem. A cada reportagem era atribuído um número e a cada resumo uma letra. Definimos como objetivo do jogo relacionar os números das reportagens às letras dos resumos corretamente, pressupondo que ao ler as reportagens e resumos os alunos deveriam identificar a idéia central em cada texto. Ao final de cinco minutos o grupo que identificasse as letras e seus respectivos números seria o vencedor.

Verificamos ao fim da experiência que surpreendentemente os alunos que se mostraram em outras ocasiões tão desinteressados não apenas aceitaram, compreenderam e superaram rapidamente e eficientemente o desafio apresentado pela professora. 0 respeito às regras do jogo e a adesão ao efeito de "ilusão" mencionado por Huizinga, levaram ainda alguns grupos à contestarem o resultado final. A liderança exercida por alguns adolescentes normalmente dentro e fora da sala de aula se revelou um estímulo fundamental ao seu grupo, despertado em parte pelo clima de competição que se estabeleceu. Avaliou-se ao final da atividade que as equipes se organizaram para realizar as leituras e cumprir a tarefa, em cooperação e tranqüilidade, atitudes pouco manifestas nesta faixa etária. Mais do que estimular a capacidade de leitura, verificou-se que esta está relacionada em parte à uma escolha do próprio aluno, depende da significação que ele confere à uma tarefa proposta pelo professor e pela escola. Como não há o imperativo da nota, do prestígio cultural, ou da expectativa da ascensão social o jovem escolhe qual texto vale a pena ser lido e que atividade ele deseja realizar.

Trabalhando com alunos de condição social bem diversa em $5^{a}$ e $6^{a}$ séries do Colégio Pedro II no Rio de Janeiro, entre 2005 e 2007, pudemos perceber outras consequêencias da utilização do jogo para construção ou consolidação de conteúdos e conceitos. Um jogo fácil de preparar, batizado por nós de "Quiz" estimula igualmente à competição. Divididos em quatro grupos com aproximadamente oito alunos por grupo, as equipes se alternam para responder no seu turno a perguntas à respeito dos conteúdos da série. 
Priorizamos os conceitos por entender que eles contribuem para 0 desenvolvimento do pensamento teórico e são necessários para elaborações mais complexas. Perguntas como: 0 que são povos nômades? O que é a mumificação no Egito Antigo? 0 que significa a democracia? Também aliamos às perguntas conceituais outras que requerem discernimento crítico: Em que continente surgiram os primeiros membros da espécie humana? Quem podia ser cidadão na democracia da Grécia antiga?

0 grau de dificuldade das perguntas deveria crescer a cada rodada. Cada grupo responderia na sua vez e ao acertar o grupo receberia um $X$, se errasse receberia um 0 e aguardaria o próximo turno. Aquele grupo que obtivesse mais marcas $X$ seria o vencedor. A atividade auxiliou-nos a revisar conteúdos estudados através do livro didático contribuindo para levar o aluno a organizar as idéias, articulando-as oralmente, localizando e identificando conceitos, temas, formulações dentro de quadros temporais e espaciais previamente estudados.

Também praticado no início do período letivo da $6^{\text {a }}$ série, o jogo demonstrou ser ocasião propícia para a interação entre todos os integrantes do grupo, mesmo os mais tímidos ou os menos adeptos do estudo diário tornaramse importantes quando as respostas não eram tão objetivas ou imediatas. Algumas respostas corretas foram proferidas por alunos considerados medianos ou fracos pelos colegas, mas que se lembravam do significado de conceitos, classificações ou definições.

No ano de 2006 elaboramos e aplicamos um outro jogo para os alunos de 6a série do Colégio Pedro II, o "Jogo do Descobrimento", confeccionado com cartolina colorida, E.v.a, Contact Paper, com um formato adaptado do jogo proposto no livro História Crítica (Mario Schmidt) de 6a série. Este jogo, uma versão de "0 Jogo da Vida", possui um tabuleiro que representaria a trajetória da Frota de Pedro Álvares Cabral, saindo de Portugal, navegando pelo Oceano Atlântico, chegando ao Brasil e partindo para as Índias e retornando à Portugal. Formaram-se quatro grupos, cada um com sete ou oito participantes, cada qual com um peão colorido. Em uma planilha os alunos deveriam marcar os pontos recebidos ou perdidos ao longo do jogo: o número de homens, de caravelas e de presentes preciosos ou dos lucros do comércio. 0 objetivo do jogo é não só alcançar a reta final, chegando de volta à Europa - o que vale um 
determinado número de pontos e coloca fim ao jogo - mas alcançar o máximo de riqueza ao fim do percurso. Cada grupo lança o dado e percorre as casas indicadas até cair en uma casa com um ícone e com uma dada cor. Cada cor diz respeito a uma etapa da viagem, a as perguntas e desafios se relacionariam. com aquela localização geográfica. Se o grupo estivesse na casa roxa, estaria em alto mar, assim as perguntas enfocariam o conhecimento dos europeus à época, os humanistas e suas idéias, os instrumentos de navegação, o tamanho do mundo e a mentalidade renascentista, os costumes e o cotidiano durante as viagens marítimas. Ao cair nas casas de cor verde, seriam testados quanto a conhecimentos sobre a cultura dos vários povos indígenas da América.

Aos ícones das casas correspondem cartas sorteadas para os grupos. Elas determinam se receberiam um presente, negociariam especiarias, enfrentariam um desafio no Novo Mundo, teriam de responder a um enigma para mover o peão ou perderiam caravelas em um naufrágio. A maioria dos ícones trazia perguntas sobre conteúdos e conceitos estudados dentro dos tópicos de Renascimento, Expansão Marítima, África e Povos indígenas das Américas. As perguntas, com graus variados de dificuldade, freqüentemente traziam imagens coladas nas cartelas que possibilitavam os participantes, através da referência visual, recordar de um conceito ou, servindo-se da inteligência, descobrir a utilidade de um objeto fabricado pelos povos nativos da América ou da África.

Qual é a cidade atual que foi erguida pelos espanhóis sobre a antiga cidade asteca de Tenochtitlán? Qual era o nome da capital do antigo Império Inca? Relacione cinco tipos de especiarias trazidas do Oriente. 0 que é antropofagia? 0 que quer dizer etnocentrismo? Quem eram os padres jesuítas e qual sua missão no Brasil? Onde viviam os povos tupinambás quando os portugueses chegaram ao Brasil? Quando os espanhóis invadiram o império asteca, como, a princípio seus habitantes interpretaram sua chegada? Quem foram as primeiras pessoas a serem escravizadas no Brasil Colônia?-Estas são algumas das questões as quais os participantes deveriam responder. Alguns alunos atribuem suas próprias respostas corretas ao "chute". Contudo, desconhecem que até o palpite é resultado da seleção dentre uma série de opções e respostas possíveis.

Muitas casas possuem ícones que não exigem resposta. Ao cair em uma destas casas os alunos contam com o elemento sorte. A incerteza característica 
de todo jogo, está presente tanto na capacidade de responder as perguntas e enigmas, mas na dúvida se serão capazes de cumprir as metas diante dos cartões indicativos de tempestades, ilhas desertas, monstros marinhos no caminho, peste e escorbuto, piratas índios antropofágicos, naufrágios, comendas do rei. São desafios e prêmios que os jogadores têm que enfrentar enquanto marinheiros da frota. Pretendíamos desta forma explorar a característica do jogo como ilusão, para levar os alunos a imergir no cotidiano do século XVI, vivenciando os costumes, formas de pensar e os riscos sempre presentes nos empreendimentos das Grandes Navegações.

Como um jogo da vida o "Jogo do Descobrimento" requer sorte, perspicácia, conhecimentos assimilados, memória, mas também estimula a imaginação. As analogias entre a vida e o jogo presentes no conhecimento popular, expressam a idéia de que tanto em uma quanto em outra, para continuar vivendo e jogando é preciso que o sujeito tenha ilusões, possua expectativas quanto as metas a atingir no futuro e antecipe suas ações com esta finalidade. Mas na vida e no jogo,existe sempre a imprevisibilidade, dada pela sorte e pelo acaso. (MACEDO, 2006, p.63) 0 engajamento imaginativo do aluno, necessário no instante em que aceita as regras do jogo, expressava-se na reação diante dos seus erros, esquecimentos, perdas e ganhos, como se cada jogada envolvesse sua própria vida e sua história.

Nossa ação pedagógica objetivava, de um lado, partindo dos referenciais auto centrados da criança e do pré-adolescente, ampliar seu reconhecimento e compreensão dos acontecimentos externos ligados à coletividade. De outro, visava colocar em movimento os conteúdos e conceitos trabalhados e discutidos previamente com apoio do livro didático, apresentando-os não apenas como saberes abstratos e distantes, mas como prática social vivida em diferentes épocas por sujeitos históricos reais que como os próprios alunos, dispunham de um campo de possibilidades e condicionamentos sociais. A experiência resultou, além do exposto, na melhoria do comportamento e no estreitamento dos laços entre os integrantes dos grupos, já que perder o jogo significava deixar de ganhar pontos na média, todos se esforçavam para chegar às respostas.

$\mathrm{Na}$ avaliação realizada pelos alunos ao final do trimestre grande parte dos alunos da $6^{\text {a }}$ série constatou que um dos momentos mais significativos das aulas de história, havia sido o "Jogo do Descobrimento", superando filmes e 
atividades com histórias em quadrinhos e atividade de pesquisa na informática. Certa vez em um conselho de classe um menino representante de uma turma de $6^{a}$ série, indagado pelos coordenadores sobre o que seria uma "aula dinâmica", explicou que é aquela em que o professor transmite alegria e que os alunos tornam-se felizes. O "Jogo do Descobrimento", para os alunos da $6^{a}$ série cumpriu este papel, ser lúdico e sério ao mesmo tempo, sem suscitar a tensão e o rigor das certificações formais.

Outro artifício lúdico que marcou as turmas de $6^{\text {a }}$ série no ano de 2006 foi o "Bingo da História". Adaptamos o brinquedo "Bingo" vendido em lojas de departamento e papelarias ao propósito pedagógico. Nas cartelas ao invés de números, escrevemos dezoito palavras ou conceitos. Cada número de 1 a 60 dentro da roda giratória corresponde a uma pergunta elaborada pelo professor. Ao sortear um número a pergunta é lida diante da classe e os alunos devem identificar qual é a resposta e reconhecer se possuem a palavra correspondente.Como exemplo temos:

- Produção exclusiva de uma mercadoria para exportação nas colônias (monocultura)

- Política mercantilista que defendia o acúmulo de metais preciosos para o enriquecimento do país. (metalismo)

- Como eram chamados os índios não tupis (tapuias)

- Ritual de consumo de carne humana praticada por alguns povos americanos (antropofagia)

Com feijões trazidos de casa, em dupla, os alunos tinham como meta preencher pelo menos uma cartela. 0 objetivo desta atividade é de levar os alunos ao debate em sua dupla e estimulá-los a identificar semelhanças, diferenças, estabelecer comparações, exclusões, associações de conceitos e termos das cartelas à conteúdos estudados, a períodos cronológicos e a processos.

Uma última modalidade de jogo que citamos aqui se insere no tópico "A Formação do Capitalismo Industrial", batizado de "Jogo do Capitalismo", dirigido à 8 série do Colégio Pedro II, no ano de 2004. A elaboração desta atividade teve em vista explorar as capacidades de antecipação propiciado pelo jogo e a capacidade de planejamento, análise e cálculo diante de problemas e desafios propostos. Esta atividade demandou do professor uma pesquisa em revistas e na internet, para se familiarizar com o "mundo dos negócios" para 
poder orientar os alunos. Os alunos se comportariam como empresários, escolhendo uma mercadoria para montar um negócio. Batizaram a empresa, especificaram o valor unitário da mercadoria, horas e número de empregados contratados, lucratividade mensal e em quantos meses restituía-se o capital inicial em uma planilha de custos e lucros.

Alguns grupos, formados por cinco ou seis alunos elaboraram mesmo um logotipo, outros partiram para pesquisar com parentes e conhecidos para registrar valores e gastos reais para abrir o tipo de empresa escolhida. A orientação quanto às regras do jogo e à exigência de verossimilhança para preços e valores conferia aos grupos liberdade para escolher o tipo de empreendimento e mercadoria. A criatividade foi um aspecto marcante desta experiência: alguns grupos optaram por montar uma indústria de skate, outros por uma fábrica de óculos e os mais irônicos se dedicaram a "negócios ilícitos".

Em seguida propusemos algumas perguntas aos alunos: empregando a lógica e observando um gráfico feito a partir da pesquisa do DataFolha, eles deveriam responder se seria possível a uma pessoa que recebe $R \$ 260$ (o salário mínimo na época) abrir um negócio de capital inicial de $\mathrm{R} \$ 500.000$ e quanto tempo precisaria trabalhar para conseguir montá-lo. Outra pergunta pedia para 0 aluno identificar o percentual da população que disporia deste capital e poderia se tornar industrial. (segundo o gráfico mostrava este percentual era de menos de 5\%)

Neste tipo de atividade, em que a competição não era o mote fundamental, surgiram trabalhos de pesquisa e confecção minuciosos em que alunos, que tiveram dificuldades em outras atividades e avaliações, mostraram-se motivados, buscando a ajuda de familiares ou conhecidos para obter informações verossímeis para o projeto. Constatando que vivemos em uma sociedade onde a ideologia liberal hegemônica perpassa os discursos na mídia, no interior da família, no Estado, nas instituições de ensino e apresenta a "solução" para as dificuldades individuais através do "empreendedorismo". Sendo assim os jovens são estimulados a se formarem para abrir seu próprio negócio ou quando não podem fazê-lo, para vender produtos e aumentar a produtividade de indústrias nas quais anseiam por trabalhar. Partimos desta visão corrente e dirigimos os alunos para refletir sobre os aspectos estruturantes da sociedade industrial e seu impacto sobre a vida das pessoas. Indispensáveis para os nossos propósitos, as 
perguntas respondidas ao final da atividade propiciaram aos estudantes descobrirem que se trata de ilusão, a promessa de que qualquer indivíduo pode entrar no jogo do capitalismo. Assim, ele compreende o mecanismo de exclusão que opera dentro do capitalismo e a razão das desigualdades sociais profundas que vivencia no cotidiano.

Para concluir, consideramos que a utilização de jogos na sala de aula para o ensino de história traz resultados muito satisfatórios. Ao imitar o cotidiano, mas dissociar-se inteiramente dele, o jogo cria espaços para a criatividade, para a imaginação e para a comparação com outras realidades históricas e modos de vida de outros povos. É uma atividade que requer a destreza, a concentração, a intuição, a cooperação, estimula a competição criando a sensação de um espaço livre de regras e de imposições. Ao sentir-se livre da avaliação dos adultos, e da punição no caso do fracasso, os alunos aderem seriamente ao jogo e a suas regras com o propósito e a expectativa de cumprir as metas. Esta adesão torna a ação pedagógica possível, faz com professores e alunos envolvidos no mesmo projeto, na mesma sintonia falem a mesma linguagem, aquela estabelecida pelas regras do jogo.

\section{Referências}

ALMEIDA, Danielle Barbosa Lins de. "Sobre brinquedos e infância: aspectos da experiência e da cultura do brincar"'In: Educação e Sociedade. Campinas: vol 27, n.95, p.541-551, maio/ago.2006.

BENJAMIN, Walter. Reflexões sobre a criança, o brinquedo e a educação.São Paulo: Duas cidades/ed.34, 2002.

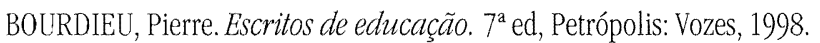

FERMIANO, Maria A. Belintane. "O Jogo como um instrumento de trabalho no ensino de História? História Hoje. ANPUH. vol. 3. n 07, julho 2005. Disponivel em: http:www.anpuh.uepg.br/históriahoje/vol3n7/maria.htm

FOUCAULT, Michel. Microfísica do Poder.2 $2^{\mathrm{a}}$ ed, Rio de Janeiro: Graal,1979.

HUIZINGA, Johan. Homo ludens.O jogo como elemento de cultura.São Paulo: Perspectiva, 1980. 
KISHIMOTO, Tizuko Morchida (org.).Jogo, brinquedo, brincadeira e a educação. $8^{a}$ ed, São Paulo: Cortez, 2005.

MACEDO, Lino de; MACHADO, Nilson José. Jogo e projeto.São Paulo: Summus editorial, 2006.

MOREIRA, Antônio Flávio Barbosa. "A Formação de professores e o aluno das camadas populares: subsídios para debate" IN: ALVES, Nilda (org.).Formação de Professores, Pensar e Fazer. São Paulo: Cortez, 1992.

PARAMETROS CURRICULARES NACIONAIS - História . $5^{\text {a a }} 8^{a}$ série.Secretaria de Ensino Fundamental, Brasília, Mec, SEF, 1998.

\section{Ludic and serious: experiments involving games in history teaching}

\section{Abstract}

This article discusses the role of play and games in the learning of concepts and contents at history lessons, based on activities and experiences lead during the years 2001 to 2007 at State's schools in Rio de Janeiro. It analyses the characteristics of games, simultaneously fun and seriousness, leading to positive results and encouraging pupils to analyse, synthesize and handle concepts and knowledge necessary to the formation of historical thinking.

Key-words: Ludic, Games, History teaching, Learning strategies 
Figura 01

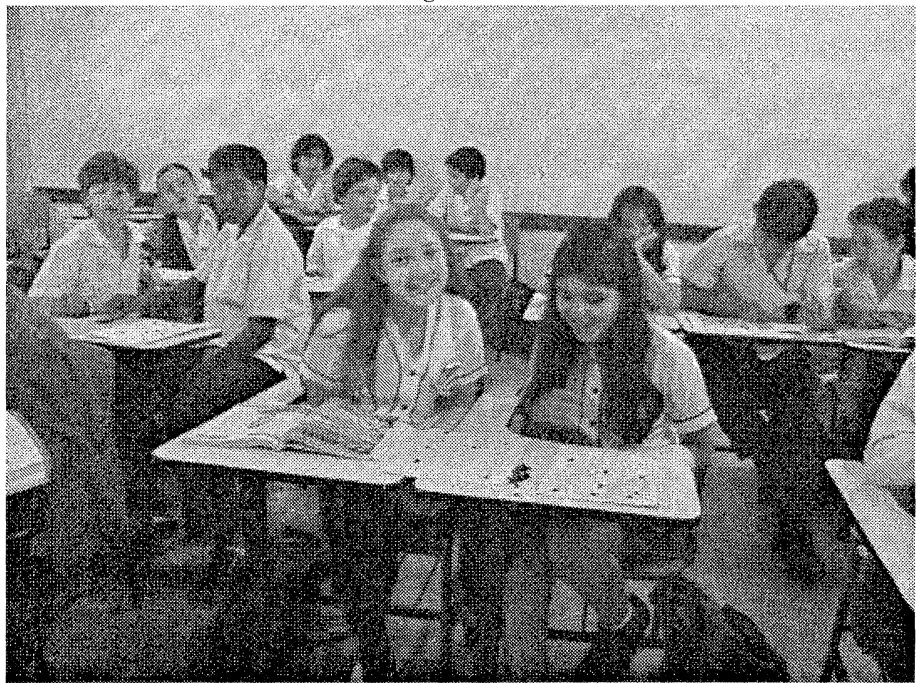

Alunas da 6ª série do Colégio Pedro II ano 2006 durante o "Bingo da História". Foto da autora.

Figura 02

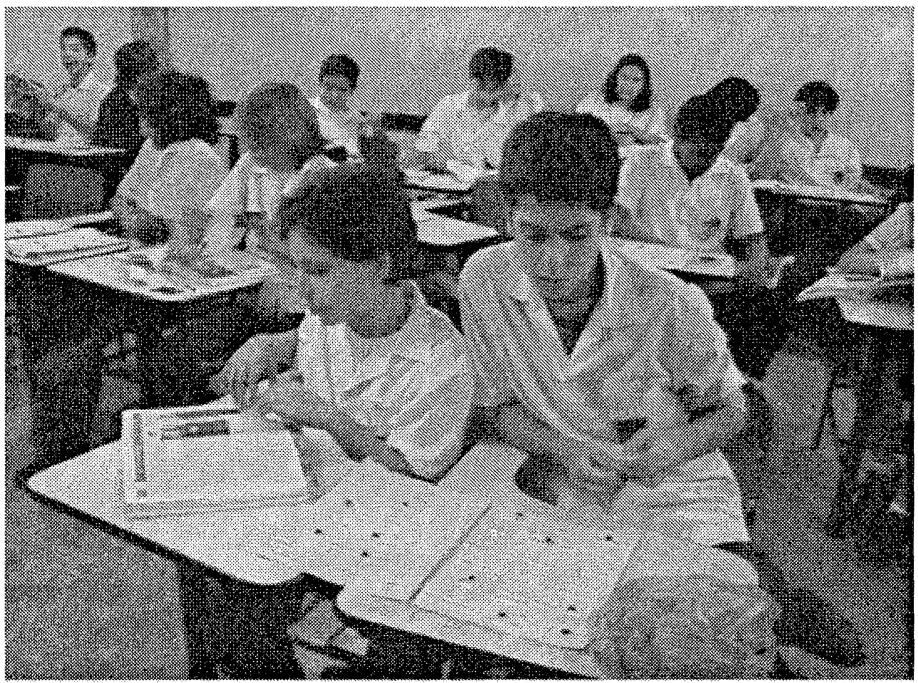

Alunos da 6 a série do Colégio Pedro II ano 2006, durante o "Bingo da História". Foto da autora 
Figura 03

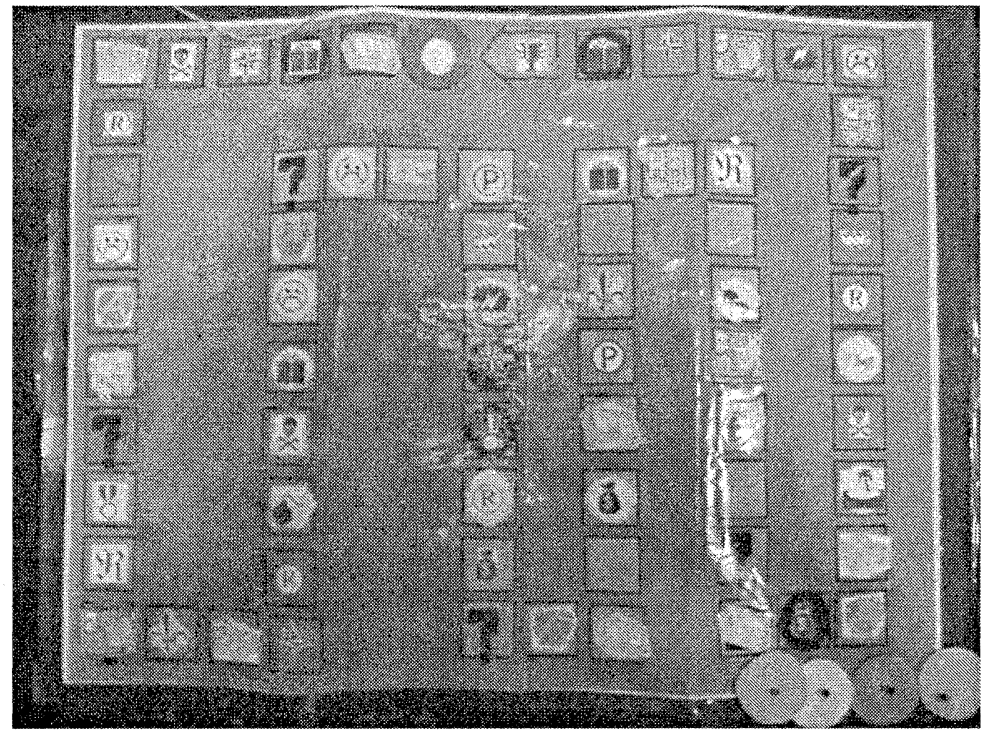

Tabuleiro do "Jogo do Descobrimento". Foto da autora. 